\title{
Gastrin promotes the metastasis of gastric carcinoma through the $\beta$-catenin/TCF-4 pathway
}

\author{
KUN ZHUANG $^{1.2}$, YUAN YAN ${ }^{1}$, XIN ZHANG $^{2}$, JUN ZHANG ${ }^{1}$, LINGXIA ZHANG $^{2}$ and KUN HAN ${ }^{2}$ \\ ${ }^{1}$ Division of Gastroenterology, The Second Affiliated Hospital, Xi'an Jiaotong University; \\ ${ }^{2}$ Division of Gastroenterology, Xi'an Central Hospital, Xi'an, Shaanxi 710003, P.R. China
}

Received February 17, 2016; Accepted March 26, 2016

DOI: $10.3892 /$ or.2016.4943

\begin{abstract}
Gastric cancer is the most common epithelial malignancy and the second leading cause of cancer-related death worldwide; metastasis is a crucial factor in the progression of gastric cancer. The present study applied gastrin-17 amide (G-17) in SGC7901 cells. The results showed that G-17 promoted the cell cycle by accelerating the G0/G1 phase and by increasing the cell proliferation rate by binding to the gastrin receptor. The migratory and invasive abilities of the SGC7901 cells were increased by G-17. The expression levels of matrix metalloproteinase (MMP)-7, MMP-9 and vascular endothelial growth factor (VEGF) were enhanced by $\mathrm{G}-17$ as well. Moreover, G-17 caused the overexpression of $\beta$-catenin and TCF-4. G-17 also caused a preferential cytoplasmic and nuclear localization of $\beta$-catenin with a high TOP-FLASH activity. Finally, axin reduced the migratory and invasive abilities of the SGC7901 cells, and inhibited the expression of $\beta$-catenin, TCF-4, MMP-7, MMP-9 and VEGF; these effects were counteracted by adding G-17. In summary, the present study confirmed the proliferation and metastasis-promoting role of G-17 via binding to the gastrin receptor, and the $\beta$-catenin/TCF-4 pathway was found to be essential for mediating G-17-induced metastasis in gastric cancer. These results may provide a novel gene target for the treatment of gastric cancer.
\end{abstract}

Correspondence to: Dr Jun Zhang, Division of Gastroenterology, The Second Affiliated Hospital, Xi'an Jiaotong University, 157 Xi Wu Road, Xi'an, Shaanxi 710003, P.R. China

E-mail: junzhangjtu@163.com

Abbreviations: G-17, gastrin-17 amide; CCK-B, cholecystokinin-B; PGL, proglumide; TCF, T-cell factor; MMP, matrix metalloproteinase; VEGF, vascular endothelial growth factor

Key words: gastric cancer, gastrin-17 amide, gastrin receptor, metastasis, $\beta$-catenin

\section{Introduction}

Gastric cancer is one of the most common epithelial malignancies and the second leading cause of cancer-related death worldwide (1). In most patients, gastric cancer is diagnosed at an advanced stage, accompanied by extensive invasion and lymphatic metastasis, resulting in the highest mortality rate among cancers (2). The metastasis of gastric cancer involves multiple steps and requires the accumulation of the altered expression of many different genes (3). At present, the mechanisms involved in gastric cancer metastasis are not fully clear and successful therapeutic strategies are limited. Therefore, the investigation of new agents, particularly targeted agents (4), and understanding of the molecular mechanisms involved in gastric cancer metastasis are vital and may provide novel avenues for targeted therapy of gastric cancer.

Gastrin, an important gastrointestinal (GI) hormone, is involved in the stimulation of gastric acid secretion and epithelial proliferation of the GI tract (5). Most gastrin is synthesized in antroduodenal G-cells, where progastrin matures to bioactive carboxyamidated gastrins through multiple modifications (6). The gastrin-17 amide (G-17), accounts for more than $90 \%$ of the G-cell synthesized gastrin in most mammals (7). In vitro studies have shown that gastrin stimulates the proliferation of gastric cancer cell lines through the induction of specific mitogen activated protein kinase (8). Transgenic mice overexpressing G-17 were found to exhibit enhanced development and progression of invasive gastric cancer (9). However, the direct role of gastrin in the promotion of gastric carcinogenesis remains elusive.

GI peptides, including gastrin and cholecystokinin (CCK), are members of a structurally diverse group of molecular messengers that play important roles in the control of appetite and hormonal secretion (10). The cholecystokinin-B (CCK-B)/gastrin receptor belongs to the seven transmembrane G-protein-coupled receptor superfamily. The CCK-B receptor on the basolateral domain of the cell membrane is immunoreactive and displays high-affinity binding ability to gastrin (11). It has been widely accepted that gastrin, a trophic factor, promotes the growth of cancer cells both in vitro and in vivo through the $\mathrm{CCK}-\mathrm{B}$ receptor, and the expression levels of the gastrin gene and CCK-B receptor are closely related to the invasiveness of cancer cells (12). These studies indicate the need for further research to establish a direct link between the 
gastrin/CCK-B receptor pathway and the metastasis of gastric cancer.

Activation of Wnt signaling involves the inhibition of $\beta$-catenin degradation, resulting in the nuclear accumulation of $\beta$-catenin and transcriptional activation of $\mathrm{T}$-cell factor/lymphoid-enhancing factor (TCF/LEF) target genes (13). Gastrin has been shown to be a functionally relevant downstream target of the Wnt signaling pathway (4). Studies have indicated that incompletely processed gastrins are capable of inducing metastatic processes in colon cancers both in vitro and in vivo (14). Additionally, Wnt pathway activation was found to contribute to carcinogenesis in a subset of gastric adenocarcinomas (15). However, the underlying mechanism of gastrins in regulating gastric cancer metastasis is still unclear.

In the present study, we aimed to identify the role of G-17 in the context of gastric cancer. We found that $\mathrm{G}-17$ promoted the expression levels of $\beta$-catenin and TCF- 4 in gastric cancer cell lines. In addition, G-17 increased the metastasis of SGC7901 cells by inducing $\beta$-catenin nuclear translocation. Taken together, our results suggest that G-17 is a pro-metastatic factor, and may therefore provide a novel therapeutic target for gastric cancer.

\section{Materials and methods}

Cell lines and cultures. Cell plates were pre-covered with Matrigel (BD Biosciences, Shanghai, China) at $5 \mu \mathrm{g} / \mathrm{cm}^{2}$. Human gastric cancer SGC7901 cells were maintained in Dulbecco's modified Eagle's medium (DMEM) containing $10 \%$ fetal bovine serum (FBS) supplemented with $100 \mathrm{U} / \mathrm{ml}$ penicillin and $100 \mathrm{mg} / \mathrm{ml}$ streptomycin at $37^{\circ} \mathrm{C}$ in $5 \% \mathrm{CO}_{2}$. SGC7901 cells were divided into four groups: control group, cells without any treatment; the G-17 group, cells incubated with $1 \times 10^{-7} \mathrm{~mol} / 1 \mathrm{G}-17$; the proglumide (PGL) group, cells incubated with $1 \times 10^{-7} \mathrm{~mol} / \mathrm{l} \mathrm{PGL}$, which is a gastrin receptor antagonist; and the G-17 + PGL group, cells incubated concur-

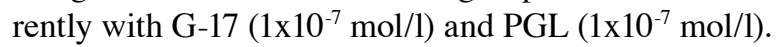

Western blot analysis. A total of $25 \mu \mathrm{g}$ of proteins was loaded and separated via sodium dodecyl sulfate-polyacrylamide gel electrophoresis, and then electrotransferred to nitrocellulose membranes (Amersham, Little Chalfont, UK). The membranes were then blocked in $2.5 \%$ non-fat milk for $1 \mathrm{~h}$ at $37^{\circ} \mathrm{C}$. After washing with Tris-buffered saline with Tween-20, the membranes were incubated with primary antibodies against $\beta$-catenin, TCF-4, matrix metalloproteinase (MMP)-7, MMP-9, vascular endothelial growth factor (VEGF) and $\beta$-actin (Santa Cruz Biotechnology, Santa Cruz, CA, USA) at $4^{\circ} \mathrm{C}$ overnight. Then, the peroxidase-conjugated secondary antibody (Boster Corporation, Wuhan, Hubei, China) diluted in 1:1,000 was added and incubated for $1 \mathrm{~h}$ at room temperature. The immunoreactive protein bands were then visualized using an enhanced chemiluminescence detection system (Amersham).

Cell cycle analysis. Cell cycle analysis was determined by flow cytometry (BD Biosciences, Franklin Lakes, NJ, USA). SGC7901 cells were harvested, washed with phosphate-buffered saline (PBS), fixed with $75 \%$ ethanol overnight at $4^{\circ} \mathrm{C}$, and then incubated with RNase at $37^{\circ} \mathrm{C}$ for $30 \mathrm{~min}$. Cell nuclei were stained with propidium iodide for $30 \mathrm{~min}$. A total of $10^{4}$ nuclei were examined in a FACSCalibur flow cytometer, and DNA histograms were analyzed by CellQuest software (both from Becton-Dickinson, Mountain View, CA, USA). Results are presented as the percentage of cells in each phase.

MTT assay. Cell viability was assessed using 3-(4,5-dimethylthiazol-2-yl)-2,5-diphenyltetrazolium bromide (MTT) assay. Cells were transfected according to the above description and were seeded into 96 -well plates at $6 \times 10^{3}$ cells/well. The surviving fractions were determined at $0,24,48,72,96$ and $120 \mathrm{~h}$. Thereafter, the old medium was discarded and fresh medium containing MTT (5 mg/ml MTT in PBS; Sangon, Shanghai, China) was added and incubated for an additional $4 \mathrm{~h}$. Then, cell viability was measured with a spectrophotometer (Bio-Rad Laboratories, Hercules, CA, USA) at $470 \mathrm{~nm}$. Each experiment was performed in triplicate.

Wound healing assay. The CytoSelect 24-well wound healing assay (Cell Biolabs, Inc., San Diego, CA, USA) was used to analyze the migration of SGC7901 cells. The assay was performed according to the manufacturer's recommendations using $2 \times 10^{3}$ cells/well. Image acquisition of wound fields was carried out after the removal of inserts $(0 \mathrm{~h})$ and wound closure documentation was completed after $24 \mathrm{~h}$ with a phasecontrast microscope (Leica DM IL) equipped with a digital camera (Leica DFC300FX) (both from Leica Microsystems, Wetzlar, Germany). Image analysis was conducted by Adobe Photoshop CS7 software.

Transwell invasion assay. Transwell membranes coated with Matrigel (Becton-Dickinson, Franklin Lakes, NJ, USA) were used to assay the invasion of the SGC7901 cells in vitro. Cells were plated at $2 \times 10^{4} /$ well in the upper chamber in serum-free medium, and $20 \%$ FBS was added to the medium in the lower chamber. After incubation for $24 \mathrm{~h}$, the non-invading cells were removed from the top well with a cotton swab, while the bottom cells were fixed in $95 \%$ ethanol, and stained with hematoxylin. The cell numbers were determined by counting the penetrating cells under a microscope at a magnification of x200 in 10 random fields in each well. Each experiment was performed in triplicate.

TOP/FOP-FLASH luciferase reporter assay. The assay was conducted according to a previously study (16); each well was incubated with a mixture containing $20 \mu \mathrm{l}$ of serum-free DMEM, $0.6 \mu \mathrm{l}$ of FuGENE, $0.15 \mu \mathrm{g}$ of the firefly luciferase reporter plasmid, $0.15 \mu \mathrm{g}$ of the $\beta$-catenin expression vector, $0.15 \mu \mathrm{g}$ of the TCF-4 expression vector, and $0.8 \mathrm{ng}$ of the Renilla luciferase vector phRG-TK. Then, $24 \mathrm{~h}$ after transfection, the cells were lysed in $50 \mu 1$ of passive lysis buffer, and the luciferase activity was determined using a luminometer using the Dual Luciferase Assay System (Promega) on $20 \mu \mathrm{l}$ of lysate. Results are expressed as fold induction. Fold induction was determined by normalizing each firefly luciferase value to the Renilla luciferase internal control value and by dividing these normalized values with the mean normalized value of the corresponding reporter construct transfected with the empty expression vectors. 

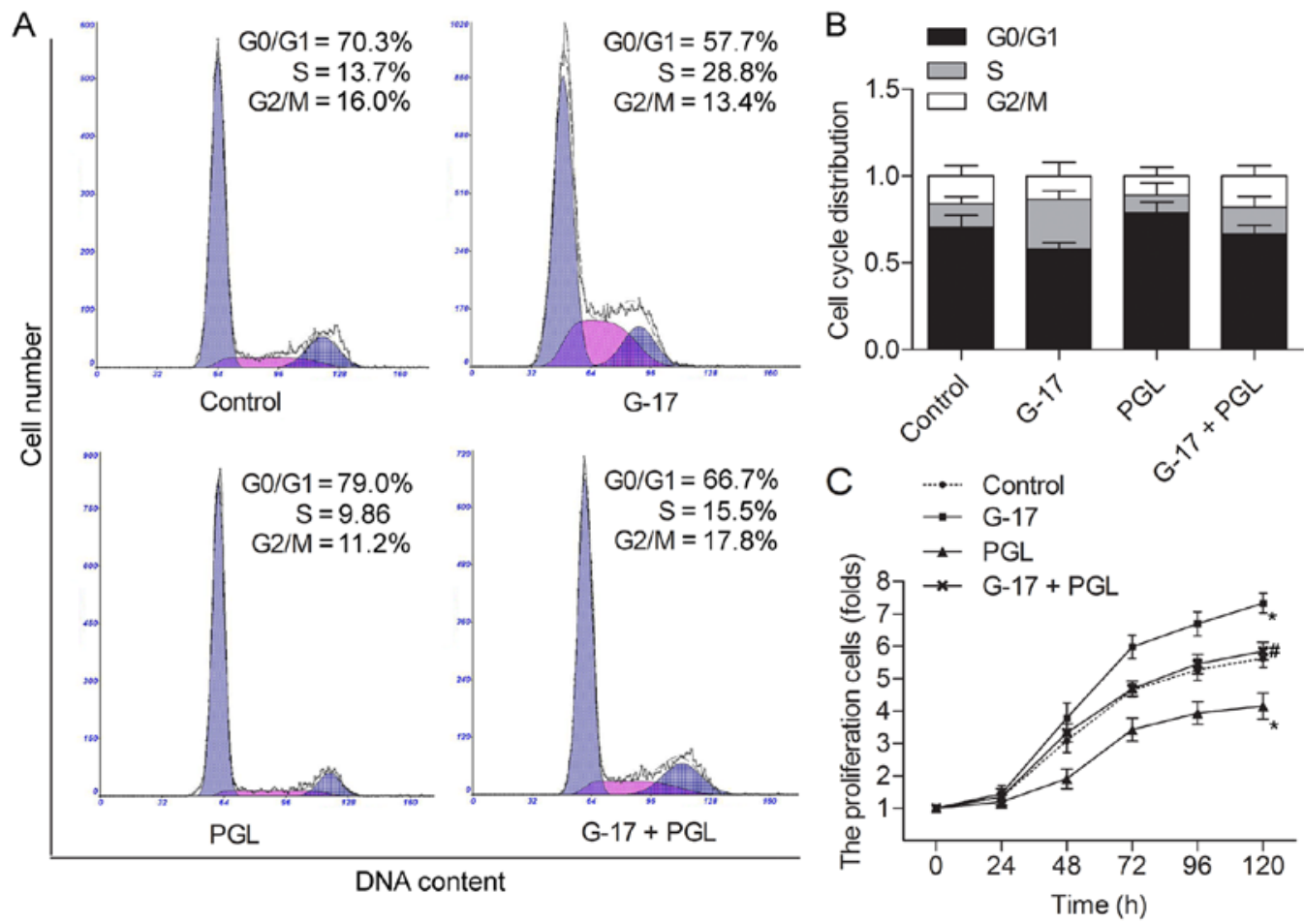

Figure 1. G-17 accelerates the cell cycle progression and proliferation of SGC7901 cells. Control group, cells without any treatment; G-17 group, cells incu-

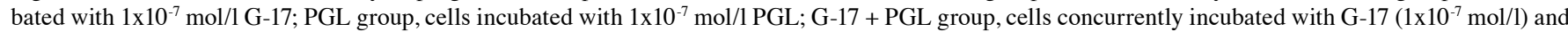
PGL (1x10 $\left.10^{-7} \mathrm{~mol} / \mathrm{l}\right)$. (A) Cell cycle analysis of SGC7901 cells was determined by flow cytometric analysis. (B) The distribution of G0/G1, S and G2/M phases was evaluated in the SGC7901 cells treated with G-17 or/and PGL for 48 h. (C) The proliferation of SGC7901 cells was determined at the time points 0, 24, 48, 96 and $120 \mathrm{~h}$ by MTT assays. All experiments were repeated thrice with three replicates; ${ }^{*} \mathrm{P}<0.05$ vs. the control group, ${ }^{\prime \prime} \mathrm{P}<0.05$ vs. the PGL group.

Immunofluorescence staining. Fluorescent cells were cultured on a 8-well chamber CultureSlides (Becton-Dickinson, Bedford, MA, USA). After $8 \mathrm{~h}$, the cells were fixed in $3 \%$ paraformaldehyde in PBS at room temperature for $8 \mathrm{~min}$, then permeabilized with $0.2 \%$ Triton $\mathrm{X}-100$ for $15 \mathrm{~min}$ at room temperature. After washing in PBS, the cells were incubated with primary mouse anti- $\beta$-catenin monoclonal antibody (1 mg/ml; Transduction Laboratories, Lexington, KY, USA) at $4{ }^{\circ} \mathrm{C}$ overnight. After washing, the cells were incubated with biotinylated goat anti-mouse IgG (Pierce, Rockford, IL, USA) at room temperature for $1 \mathrm{~h}$. The immunoreactivity was revealed using Alexa 568-conjugated streptavidin (Molecular Probes, Eugene, OR, USA), and the cells were counterstained with $10 \mathrm{mg} / \mathrm{ml}$ 4',6-diamidino-2-phenylindole dihydrochloride (DAPI). The cells were examined under a Nikon fluorescence microscope (Image Systems, Columbia, MD, USA).

Statistical analysis. All results are presented as mean \pm SD. The statistical significance of the studies was analyzed using the Student's t-test. The difference was considered statistically significant at $\mathrm{P}<0.05$.

\section{Results}

G-17 accelerates cell cycle progression and proliferation of SGC7901 cells. To investigate the impact of G-17 on the SGC7901 cells, we studied whether G-17 was capable of affecting the cell cycle and proliferation. Flow cytometric analysis indicated that the G0/G1 phase in the SGC7901 cells was accelerated in the G-17 group, and an accumulation of G0/ G1 phase in the PGL group compared with the control group. However, the G0/G1 phase was shortened in the G-17 + PGL group compared with the PGL group (Fig. 1A and B). These results indicated an activation of G0/G1 progression in the SGC7901 cells following incubation with G-17. The cell proliferation assay was performed in SGC7901 cells; G-17 was observed to strongly increase the cell growth compared with the control group, and the decreased cell numbers caused by PGL were balanced by G-17 treatment $(\mathrm{P}<0.05)$ (Fig. 1C). These findings demonstrated that G-17 promoted the cell cycle by accelerating the G0/G1 phase and increasing cell proliferation levels in the SGC7901 cells.

G-17 increases the migration and invasion of SGC7901 cells. Given the impact of G-17 on the cell cycle and proliferation of SGC7901 cells, scratch assays were next carried out to measure the motility of the SGC7901 cells induced by G-17. The G-17 group showed an almost complete closure of the gap, whereas the PGL group reduced the gap by only $20 \%$ compared with that noted in the control group $(\mathrm{P}<0.05)$, indicating that G-17 promoted the migration of SGC7901 cells via binding to its receptor. In addition, the wound closed by nearly $75 \%$ in the G-17 + PGL group ( $\mathrm{P}<0.05)$ (Fig. 2A and $\mathrm{B})$, indicating the antagonistic effect of G-17 towards PGL. The results of the Transwell assay were coincident with the results of the scratch assays. The number of invasive SGC7901 cells was increased by G-17, but decreased by PGL compared with the control group, and the motile ability was recovered in the 

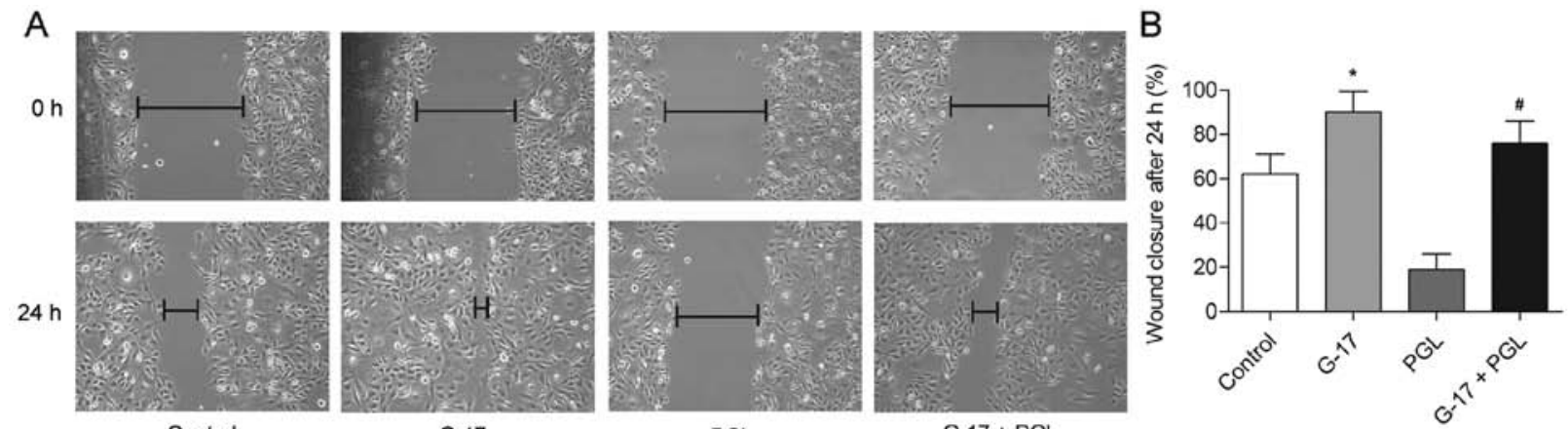

C
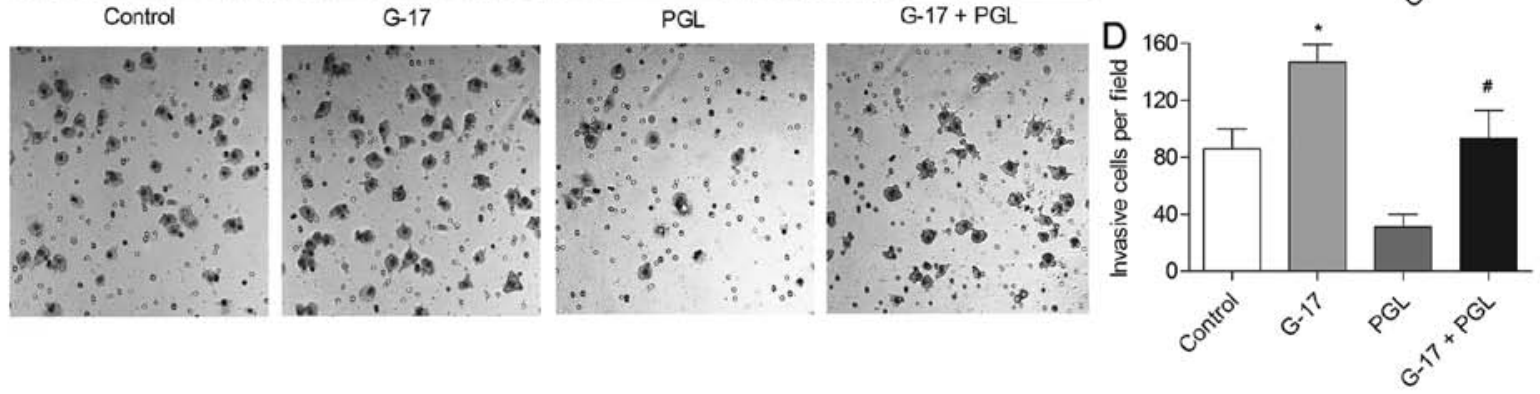

Figure 2. G-17 antagonizes PGL and increases the metastasis of SGC7901 cells. (A) Wound-healing assays of the SGC7901 cells treated with G-17 or/and PGL for $24 \mathrm{~h}$. (B) Histogram showing the wound-healing assays of SGC7901 cells in each group. (C) Transwell assays of SGC7901 cells treated with G-17 or/and PGL for 48 h. (D) Histogram illustrating the Transwell assays of SGC7901 cells in each group. All the experiments were repeated thrice with three replicates; ${ }^{*} \mathrm{P}<0.05$ vs. the control group, ${ }^{,} \mathrm{P}<0.05$ vs. the PGL group.

A

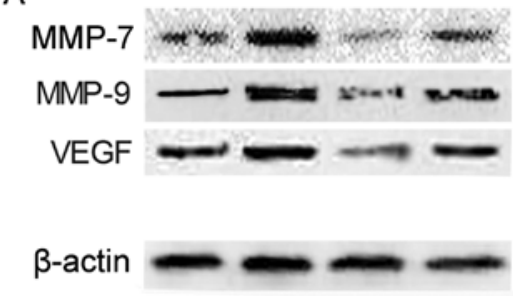

C

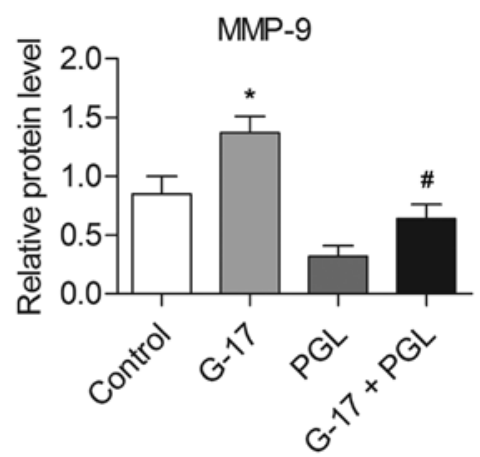

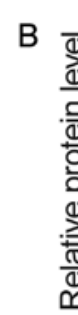

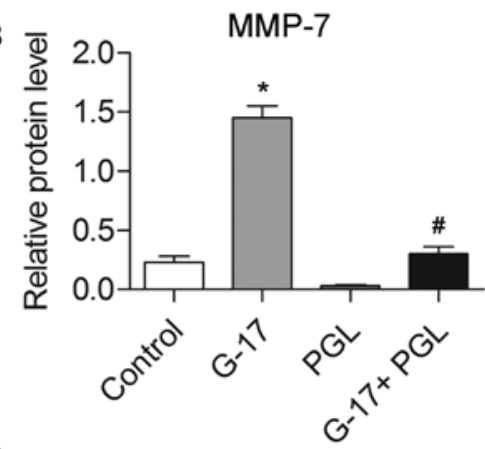

$\mathrm{D}$

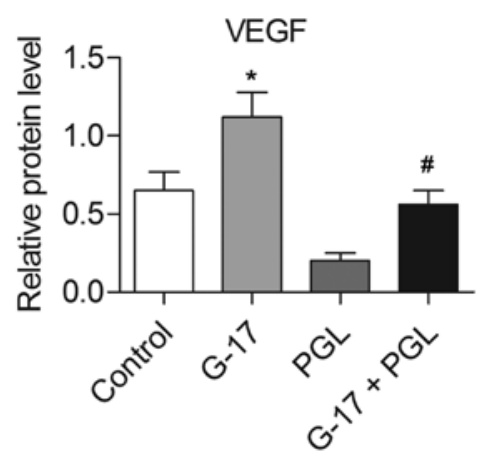

Figure 3. G-17 promotes the expression of cancer metastasis-associated proteins. (A) The expression levels of MMP-7, MMP-9 and VEGF were detected in the SGC7901 cells by western blotting; relative protein expression levels of (B) MMP-7, (C) MMP-9 and (D) VEGF were quantified using Image-Pro Plus 6.0 software and normalized to $\beta$-actin. Data are represented as the mean \pm SD of all three experiments; ${ }^{*} \mathrm{P}<0.05$ vs. the control group, ${ }^{\#} \mathrm{P}<0.05$ vs. the $\mathrm{PGL}$ group.

G-17 + PGL group compared with that noted in the PGL group $(\mathrm{P}<0.05)$ (Fig. 2C and D). These observations suggest that $\mathrm{G}-17$ is a positive metastatic regulator of gastric cancer.

G-17 promotes the expression levels of cancer metastasisassociated proteins. The expression levels of MMP-7, MMP-9 and VEGF were determined by western blotting. The results indicated that the levels of the three proteins were increased in the G-17 group and decreased in the PGL group compared with these levels in the control group $(\mathrm{P}<0.05)$, while the G-17 + PGL group exhibited higher expression levels of MMP-7, MMP-9 and VEGF in comparison with the PGL 

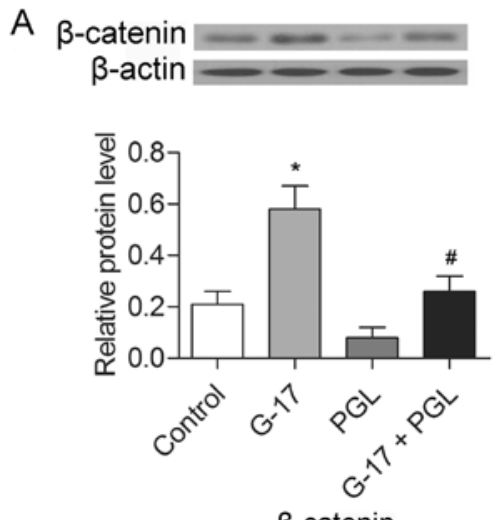

$\beta$-catenin
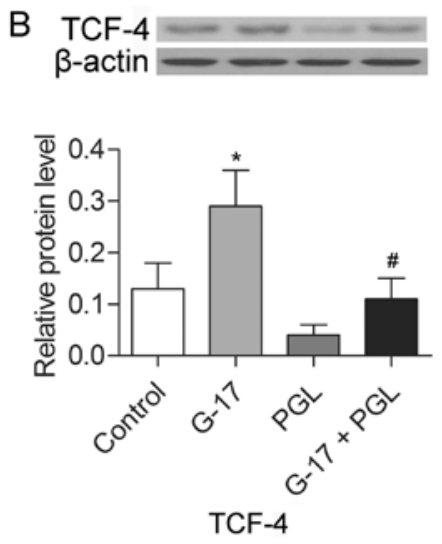

Figure 4. G-17 promotes the expression levels of $\beta$-catenin and TCF-4 by binding to the G-17 receptor. SGC7901 cells were divided into four groups: control, G-17, PGL and G-17 + PGL groups. (A) The expression of $\beta$-catenin was detected in the SGC7901 cells by western blotting, with relative protein expression quantified using Image-Pro Plus 6.0 software and normalized to $\beta$-actin. (B) A similar western blot assay was performed to detect the expression of TCF-4. Data are represented as the mean $\pm \mathrm{SD}$ of three experiments; ${ }^{*} \mathrm{P}<0.05$ vs. the control group, ${ }^{\prime} \mathrm{P}<0.05$ vs. the PGL group.
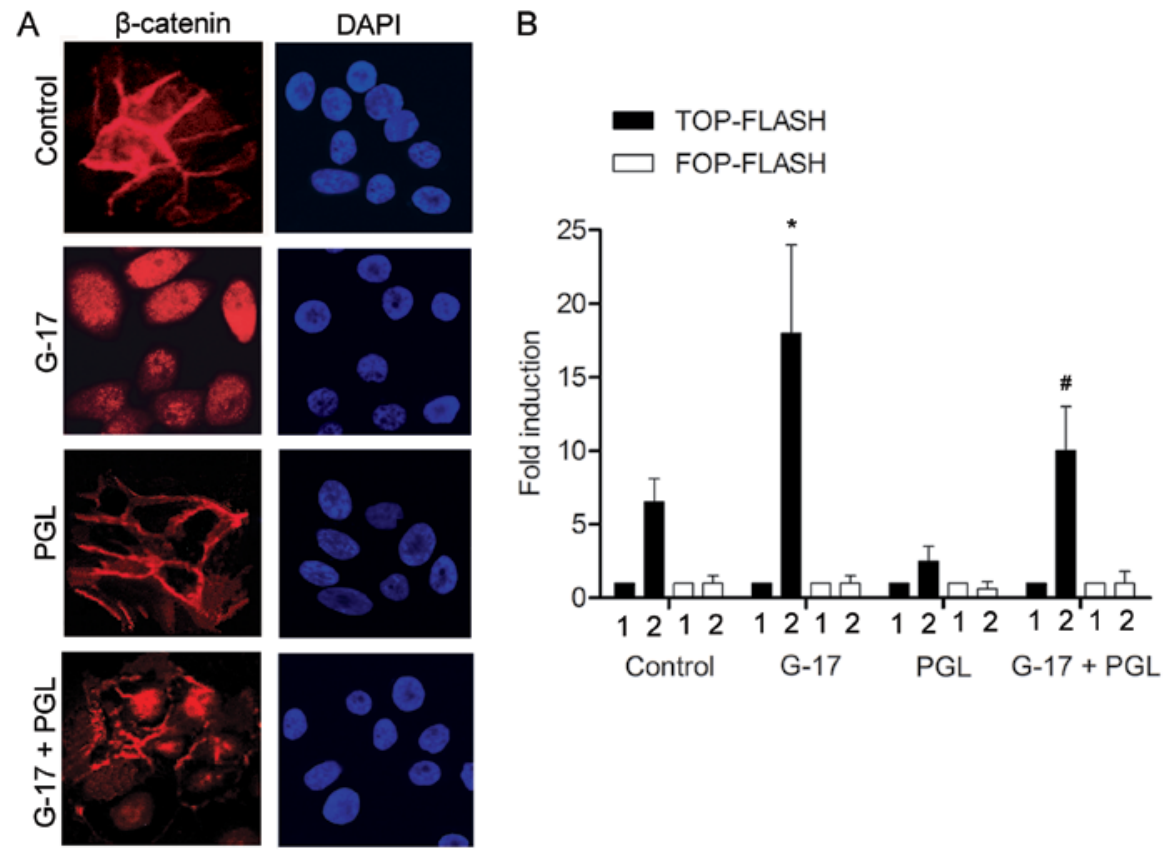

Figure 5. G-17 activates the $\beta$-catenin nuclear translocation in SGC7901 cells. (A) Immunofluorescence staining of $\beta$-catenin in the SGC7901 cells were stained for $\beta$-catenin and counterstained with DAPI as indicated. (B) SGC7901 cells were transfected with the TOP- or FOP-FLASH firefly luciferase reporter plasmids with the empty expression vectors (lane 1) or with the $\beta$-catenin and TCF-4 expression vectors (lane 2). Data are presented as fold induction relative to the co-transfection of the reporter plasmid (either TOP- or FOP-FLASH) with the empty expression vectors and expressed as means \pm SD in at least three experiments; ${ }^{*} \mathrm{P}<0.05$ vs. the control group, ${ }^{,} \mathrm{P}<0.05$ vs. the PGL group.

group $(\mathrm{P}<0.05)$ (Fig. 3). The increased expression of migration-related proteins further confirmed of the effect of G-17, which promotes the metastasis of SGC7901 cells.

$G-17$ promotes the expression of $\beta$-catenin and TCF-4. The expression levels of $\beta$-catenin and TCF- 4 were detected in the SGC7901 cells by western blotting. The results indicated that the levels of both $\beta$-catenin and TCF- 4 were increased in the G-17 group and decreased in the PGL group compared with the levels in the control group $(\mathrm{P}<0.05)$, while the $\mathrm{G}-17+\mathrm{PGL}$ group exhibited higher expression levels of $\beta$-catenin and TCF-4 in comparison with levels noted in the PGL group $(\mathrm{P}<0.05)$ (Fig. 4). The results indicate that $\mathrm{G}-17$ induced the activation of the $\beta$-catenin pathway via binding to the G-17 receptor in the SGC7901 cells.

$G-17$ induces the $\beta$-catenin nuclear translocation in SGC7901 cells. To further explore the mechanism involved in the metastasis of SGC7901 cells by G-17, the subcellular localization of $\beta$-catenin was evaluated. The G-17 group displayed predominantly nuclear $\beta$-catenin staining. Cells in the PGL group showed membranous $\beta$-catenin staining with minimal cytoplasmic or nuclear staining, whereas cells in the G-17 + PGL group displayed more cytoplasmic and nuclear staining of $\beta$-catenin as compared with that noted in PGL group (Fig. 5A). We then compared the ability of SGC7901 
A
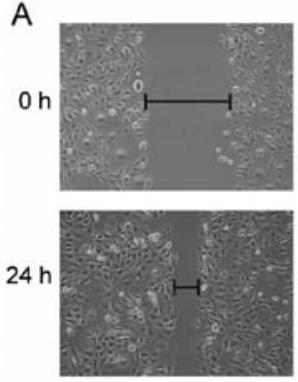

C

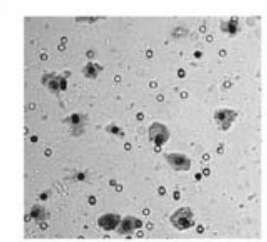

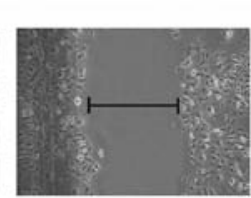

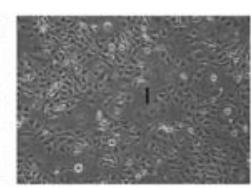

G-17

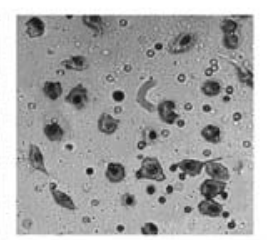

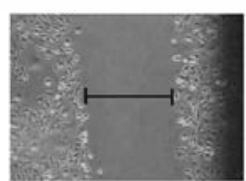

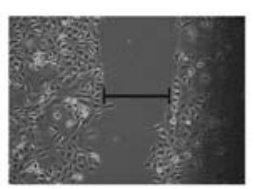

Axin

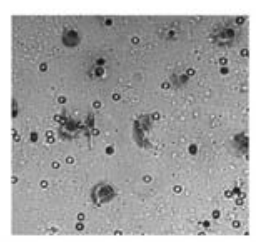

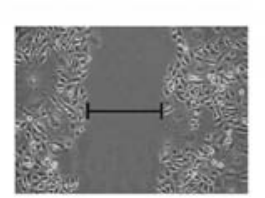

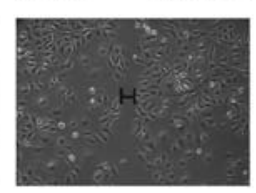

G-17+ Axin

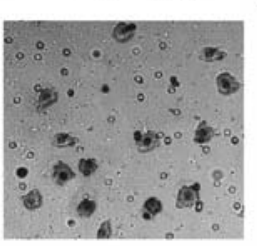

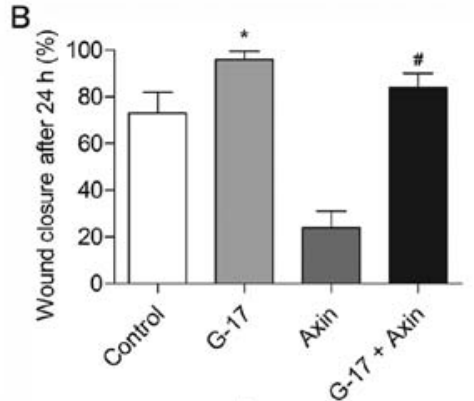

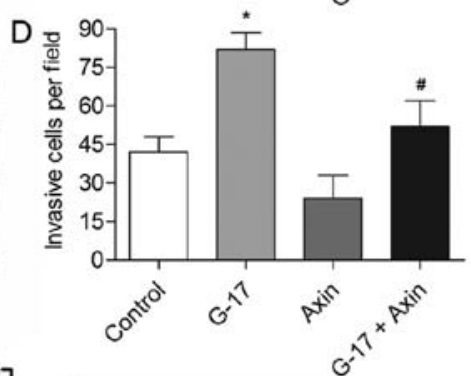

G
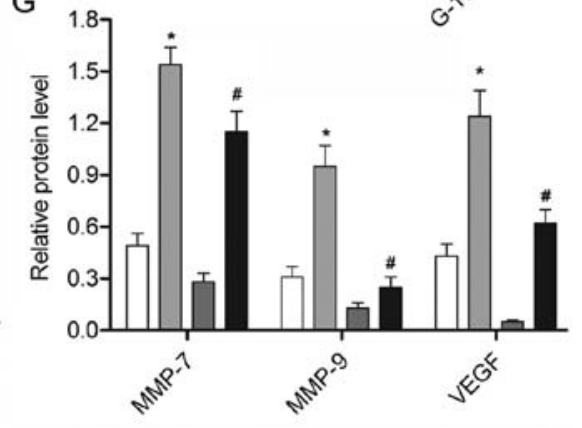

Figure 6. The $\beta$-catenin/TCF-4 pathway mediates the G-17-induced metastasis of SGC7901 cells. SGC7901 cells were divided into four groups: the control group, cells without any treatment; the G-17 group, cells incubated with $1 \times 10^{-7} \mathrm{~mol} / \mathrm{l} \mathrm{G}-17$; axin group, cells incubated with $1 \mu \mathrm{g}$ axin; and the G-17 + PGL group, cells concurrently incubated with G-17 (1x10 $\left.{ }^{-7} \mathrm{~mol} / \mathrm{l}\right)$ and $1 \mu \mathrm{g}$ axin. (A) Wound-healing assays of SGC7901 cells treated with G-17 or/and axin for $24 \mathrm{~h}$. (B) Histogram showing the quantification of wound-healing assays of SGC7901 cells in each group. (C) Transwell assays of SGC7901 cells treated with G-17 or/and axin for $48 \mathrm{~h}$. (D) Histogram illustrating the quantification of Transwell assays of SGC7901 cells in each group. (E) The expression levels of $\beta$-catenin, TCF-4, MMP-7, MMP-9 and VEGF were detected in the SGC7901 cells by western blotting. Relative protein expression of (F) $\beta$-catenin, TCF-4, (G) MMP-7, MMP-9 and VEGF were quantified using Image-Pro Plus 6.0 software and normalized to $\beta$-actin. Data are represented as the mean \pm SD of three experiments; ${ }^{*} \mathrm{P}<0.05$ vs. the control group, ${ }^{\#} \mathrm{P}<0.05$ vs. the $\mathrm{G}-17$ group.

cells in each group to transactivate the luciferase reporter plasmid containing the wild-type (TOP-FLASH) or mutated (FOP-FLASH) $\beta$-catenin/TCF binding site as regulatory elements. Cells induced by G-17 displayed a higher ability to transactivation the TOP-FLASH reporter plasmid than the control group (Fig. 5B). The G-17 + PGL group exhibited a higher TOP-FLASH transactivate activity compared with the PGL group. In accordance with our findings, showing a preferential cytoplasmic and nuclear localization of $\beta$-catenin in the G-17-induced cells, these data clearly indicate that G-17-treated cells had stronger $\beta$-catenin/TCF transcriptional activity than the untreated cells, and that G-17 promoted the nuclear translocation of $\beta$-catenin to activate the Wnt signaling pathway in the SGC7901 cells.

The $\beta$-catenin/TCF-4 pathway mediates $G$-17-induced metastasis of SGC7901 cells. The former experiment provided convincing evidence that G-17 promotes metastasis by activating the $\beta$-catenin/TCF-4 pathway; however, it is unclear whether the $\beta$-catenin/TCF-4 pathway is necessary for the G-17-induced metastasis of SGC7901 cells. Axin is known to inhibit the Wnt-signaling pathway via facilitating the phos- phorylation and thus the degradation of $\beta$-catenin (17). The results showed that the migratory and invasive abilities of the SGC7901 cells were suppressed by axin compared with these parameters in the control group $(\mathrm{P}<0.05)$ (Fig. 6A-D), suggesting the indispensable role of $\beta$-catenin in G-17-induced metastasis of SGC7901 cells. The motile ability was decreased in the G-17 + axin group compared with that noted in the G-17 group $(\mathrm{P}<0.05)$, indicating that the $\mathrm{G}-17$-induced metastasis in SGC7901 cells relies on $\beta$-catenin. The expression levels of $\beta$-catenin, TCF-4, MMP-7, MMP-9 and VEGF were strongly inhibited by axin compared with the control group. The inhibitory effect in the G-17 + axin group was detected compared with the G-17 group (Fig. 6E-G), further showing that the G-17-induced metastasis was dependent on the $\beta$-catenin/ TCF-4 pathway in the SGC7901 cells. These results indicated that the $\beta$-catenin/TCF-4 pathway is essential for mediating G-17-induced metastasis in SGC7901 cells.

\section{Discussion}

Gastric cancer is the second leading cause of cancer-related deaths worldwide (18). Gastric cancer metastasis is a crucial 
factor in the determination of the clinical staging, prognosis and survival of gastric cancer patients (19). Therefore, identifying metastatic factors and elucidating the molecular mechanisms underlying gastric cancer metastasis have become critical issues. Accumulated evidence indicates that G-17 has growthpromoting and oncogenic function in gastric cancers $(20,21)$; its role in metastasis and the relative mechanism in gastric cancer were explored in the present study.

The CCK-B receptor is widely distributed throughout the human GI tract and mediates the normal physiological function of gastrin. Gastrin has proliferative effects on various malignancies including gastric and colorectal cancers through the CCK-B receptor $(22,23)$. Gastrin and CCK have been reported to mediate the proliferative responses in a variety of normal and cancer cell model systems (20). Gastrin in particular has been implicated in accelerating the development of gastrointestinal cancers (24). Previously, Pradeep et al reported that $\mathrm{G}-17$ induced the activation of $\mathrm{G} 1$ progression in gastric adenocarcinoma cell line AGSE (25). To investigate the G-17 function in gastric cancer via binding to its receptor, a gastrin receptor antagonist, PGL was used in this research. The results indicated an activation of G1 progression following incubation with $\mathrm{G}-17$, but a retardation in the $\mathrm{G} 0 / \mathrm{G} 1$ phase with PGL. Our results demonstrated that G-17 promoted cell cycle progression by accelerating the G0/G1 phase via binding to the gastrin receptor in SGC7901 cells.

Metastasis is an important element of gastric cancer progression, and leads to a high mortality rate and poor prognosis (26). Cell invasive ability is critical for tumor metastasis (27). In the present study, the migratory and invasive abilities of the SGC7901 cells were increased following treatment with G-17, whereas they were decreased by PGL, suggesting that G-17 is a metastasis-associated biomarker in gastric cancer. Apart from G-17, microRNA-335 (28) and SOX-2 (29) were reported to be suppressors, while Y-box binding protein-1 was indicated as a promoter in the metastasis of gastric cancer (30). These findings, along with ours, indicate that potential prognostic biomarkers could serve as potential gene targets in gastric cancer metastasis treatment.

MMPs have been recognized as the most important protease family, and mediate central events in tumor progression, including invasion, metastasis and angiogenesis (31). Higher MMP-7 and MMP-9 levels were reported to be associated with the invasive phenotype of gastric cancer $(32,33)$. VEGF is a well-defined pro-angiogenic and pro-metastatic factor in numerous human cancers (34), and the upregulation of VEGF contributes to the tumor invasion and metastasis of gastric cancer (35). The expression levels of MMP-7, MMP-9 and VEGF were significantly increased by G-17, but were inhibited by PGL in the present study. The results provide further evidence of the metastasis-promoting role of G-17 in gastric cancer via binding to the gastrin receptor.

Studies indicate that $\beta$-catenin and TCF4, which are important genes in the Wnt pathway, are critical oncogenes in GI-related tumorigenesis (36). Thus, we evaluated the expression of $\beta$-catenin and TCF-4 in the SGC7901 cells. The results revealed that $\mathrm{G}-17$ induced the activation of the $\beta$-catenin pathway via binding to the gastrin receptor in the SGC7901 cells. Higher $\beta$-catenin/TCF activity induced by G-17 was measured by the TOP-/FOP-FLASH luciferase reporter assay, strongly supporting a role of G-17 in activating the $\beta$-catenin/TCF pathway in gastric cancer. Nuclear $\beta$-catenin has been reported to be the hallmark of an active Wnt pathway (37). The stimulation of $\beta$-catenin nuclear translocation further confirmed the suppressive role of G-17 in $\beta$-catenin degradation. These results were coincident with the behavior of gastrin in colorectal tumor cells, in which it prolonged the $t_{1 / 2}$ of $\beta$-catenin protein by stabilizing $\beta$-catenin (38), and demonstrated that gastrin appears to exert the nuclear translocation of $\beta$-catenin to activate the Wnt pathway in gastric cancer.

Axin is known to inhibit the Wnt-signaling pathway via facilitating the phosphorylation and the degradation of $\beta$-catenin. To investigate the necessity of the Wnt pathway in G-17-induced gastric cancer metastasis, G-17 was incubated with or without axin in the present study. The results showed that the migratory and invasive abilities of the SGC7901 cells were suppressed by axin, but recovered to some extent by $\mathrm{G}-17$. These results indicated that the $\beta$-catenin/TCF- 4 pathway is essential in mediating G-17-induced metastasis in gastric cancer, and G-17 exhibited antagonism to the $\beta$-catenin degradation by axin. The present study indicated that the APC/ axin/GSK complex is a degradation agent of $\beta$-catenin; the dissociation of the complex leads to $\beta$-catenin accumulation. The free- $\beta$-catenin then translocates to the nucleus where it binds to T-cell factors and activates the transcription of a number of genes, including c-Myc, cyclin D1 and MMP-7 (37). Compared with the effect of axin in the present study, the expression levels of $\beta$-catenin, TCF-4, MMP-7, MMP-9 and VEGF in the axin + G-17 group were enhanced, and the results confirmed the suppressive role of G-17 in $\beta$-catenin degradation in gastric cancer.

Along with these data, our present research explored an important GI hormone, G-17, in gastric cancer SGC7901 cells. Through binding to the gastrin receptor, G-17 promoted cell progression and metastasis, and activated the $\beta$-catenin/TCF-4 pathway. In addition, the $\beta$-catenin/TCF- 4 pathway was found to be essential for mediating G-17-induced metastasis and G-17 suppressed the $\beta$-catenin degradation in gastric cancer. These results offer a potential gene target for the treatment of gastric cancer.

\section{Acknowledgements}

The authors would like to thank the members of the Second Affiliated Hospital of Xi'an Jiaotong University and Xi'an Central Hospital, for providing technical support and helpful discussions concerning the present study.

\section{References}

1. Ferlay J, Shin HR, Bray F, Forman D, Mathers C and Parkin DM: Estimates of worldwide burden of cancer in 2008: GLOBOCAN 2008. Int J Cancer 127: 2893-2917, 2010.

2. Coburn NG: Lymph nodes and gastric cancer. J Surg Oncol 99: 199-206, 2009.

3. Hippo Y, Yashiro M, Ishii M, Taniguchi H, Tsutsumi S, Hirakawa K, Kodama T and Aburatani H: Differential gene expression profiles of scirrhous gastric cancer cells with high metastatic potential to peritoneum or lymph nodes. Cancer Res 61: 889-895, 2001.

4. Doi T, Muro K, Boku N, Yamada Y, Nishina T, Takiuchi H, Komatsu Y, Hamamoto Y, Ohno N, Fujita Y, et al: Multicenter phase II study of everolimus in patients with previously treated metastatic gastric cancer. J Clin Oncol 28: 1904-1910, 2010. 
5. Friis-Hansen L, Sundler F, Li Y, Gillespie PJ, Saunders TL Greenson JK, Owyang C, Rehfeld JF and Samuelson LC: Impaired gastric acid secretion in gastrin-deficient mice. Am J Physiol 274: G561-G568, 1998.

6. Rehfeld JF, Lindberg I and Friis-Hansen L: Progastrin processing differs in 7B2 and PC2 knockout animals: A role for 7B2 independent of action on PC2. FEBS Lett 510: 89-93, 2002.

7. Rehfeld JF, Hansen CP and Johnsen AH: Post-poly(Glu) cleavage and degradation modified by $\mathrm{O}$-sulfated tyrosine: A novel posttranslational processing mechanism. EMBO J 14: 389-396, 1995

8. Gutkind JS: The pathways connecting G protein-coupled receptors to the nucleus through divergent mitogen-activated protein kinase cascades. J Biol Chem 273: 1839-1842, 1998.

9. Wang TC, Dangler CA, Chen D, Goldenring JR, Koh T, Raychowdhury R, Coffey RJ, Ito S, Varro A, Dockray GJ, et al: Synergistic interaction between hypergastrinemia and Helicobacter infection in a mouse model of gastric cancer. Gastroenterology 118: 36-47, 2000.

10. Rozengurt E and Walsh JH: Gastrin, CCK, signaling, and cancer. Annu Rev Physiol 63: 49-76, 2001.

11. Kulaksiz H, Arnold R, Göke B, Maronde E, Meyer M, Fahrenholz F, Forssmann WG and Eissele R: Expression and cellspecific localization of the cholecystokinin B/gastrin receptor in the human stomach. Cell Tissue Res 299: 289-298, 2000

12. Watson SA, Morris TM, McWilliams DF, Harris J, Evans S, Smith A and Clarke PA: Potential role of endocrine gastrin in the colonic adenoma carcinoma sequence. Br J Cancer 87: 567-573, 2002.

13. Park WS, Oh RR, Park JY, Lee SH, Shin MS, Kim YS, Kim SY, Lee HK, Kim PJ, Oh ST, et al: Frequent somatic mutations of the $\beta$-catenin gene in intestinal-type gastric cancer. Cancer Res 59: 4257-4260, 1999.

14. Kermorgant S and Lehy T: Glycine-extended gastrin promotes the invasiveness of human colon cancer cells. Biochem Biophys Res Commun 285: 136-141, 2001.

15. Clements WM, Wang J, Sarnaik A, Kim OJ, MacDonald J, Fenoglio-Preiser C, Groden J and Lowy AM: $\beta$-Catenin mutation is a frequent cause of Wnt pathway activation in gastric cancer. Cancer Res 62: 3503-3506, 2002.

16. Gilles C, Polette M, Mestdagt M, Nawrocki-Raby B, Ruggeri P, Birembaut $\mathrm{P}$ and Foidart JM: Transactivation of vimentin by $\beta$-catenin in human breast cancer cells. Cancer Res 63: 2658-2664, 2003.

17. Kikuchi A: Modulation of Wnt signaling by Axin and Axil. Cytokine Growth Factor Rev 10: 255-265, 1999.

18. Crew KD and Neugut AI: Epidemiology of gastric cancer. World J Gastroenterol 12: 354-362, 2006.

19. Yang ZG, Gao L, Guo XB and Shi YL: Roles of long non-coding RNAs in gastric cancer metastasis. World J Gastroenterol 21: 5220-5230, 2015.

20. Basu A, Sondarva G, Santha S, Rana A and Rana B: Elucidation of signaling pathways that mediate gastrin-induced JNK activation and pGSK3 $3 /$ Snail induction in gastric cancer cells. Cancer Res 75 (Suppl 15): 1967, 2015. doi:10.1158/1538-7445. AM2015-1967.

21. Yakut M, Örmeci N, Erdal H, Keskin O, Karayel Z, Tutkak H and Soykan I: The association between precancerous gastric lesions and serum pepsinogens, serum gastrin, vascular endothelial growth factor, serum interleukin-1 Beta, serum toll-like receptor-4 levels and Helicobacter pylori Cag A status. Clin Res Hepatol Gastroenterol 37: 302-311, 2013.

22. Han YM, Park JM, Park SH, Hahm KB, Hong SP and Kim EH: Gastrin promotes intestinal polyposis through cholecystokinin-B receptor-mediated proliferative signaling and fostering tumor microenvironment. J Physiol Pharmacol 64: 429-437, 2013.
23. Huang BP, Lin $\mathrm{CH}$, Chen $\mathrm{YC}$ and $\mathrm{Kao} \mathrm{SH}$ : Expression of cholecystokinin receptors in colon cancer and the clinical correlation in Taiwan. Tumour Biol 37: 4579-4584, 2016.

24. Marshall KM, Laval M, Estacio O, Hudson DF, Kalitsis P, Shulkes A, Baldwin GS and Patel O: Activation by zinc of the human gastrin gene promoter in colon cancer cells in vitro and in vivo. Metallomics 7: 1390-1398, 2015.

25. Pradeep A, Sharma C, Sathyanarayana P, Albanese C, Fleming JV, Wang TC, Wolfe MM, Baker KM, Pestell RG and Rana B: Gastrin-mediated activation of cyclin D1 transcription involves $\beta$-catenin and CREB pathways in gastric cancer cells. Oncogene 23: 3689-3699, 2004.

26. Jie D, Zhongmin Z, Guoqing L, Sheng L, Yi Z, Jing W and Liang Z: Positive expression of LSD1 and negative expression of E-cadherin correlate with metastasis and poor prognosis of colon cancer. Dig Dis Sci 58: 1581-1589, 2013.

27. Pang MF and Nelson CM: Intercellular communication, the tumor microenvironment, and tumor progression. In: Intercellular Communication in Cancer. Springer, pp343-362, 2015. 10.1007/978-94-017-7380-5_13.

28. Xu Y, Zhao F, Wang Z, Song Y, Luo Y, Zhang X, Jiang L, Sun Z, Miao Z and Xu H: MicroRNA-335 acts as a metastasis suppressor in gastric cancer by targeting Bcl-w and specificity protein 1. Oncogene 31: 1398-1407, 2012.

29. Wang S, Tie J, Wang R, Hu F, Gao L, Wang W, Wang L, Li Z, $\mathrm{Hu}$ S, Tang S, et al: SOX2, a predictor of survival in gastric cancer, inhibits cell proliferation and metastasis by regulating PTEN. Cancer Lett 358: 210-219, 2015.

30. Guo T, Yu Y, Yip GWC, Baeg GH, Thike AA, Lim TK, Tan PH, Matsumoto K and Bay BH: Y-box binding protein 1 is correlated with lymph node metastasis in intestinal-type gastric cancer. Histopathology 66: 491-499, 2015.

31. Egeblad M and Werb Z: New functions for the matrix metalloproteinases in cancer progression. Nat Rev Cancer 2: 161-174, 2002.

32. Li Z, Zhang D, Zhang H, Miao Z, Tang Y, Sun G and Dai D: Prediction of peritoneal recurrence by the mRNA level of CEA and MMP-7 in peritoneal lavage of gastric cancer patients. Tumour Biol 35: 3463-3470, 2014.

33. Shimjura T, Dagher A, Ebi M, Yamada T, Yamada T, Joh T and Moses MA: Potential of urinary MMP-9/NGAL complex as a novel biomarker for the early detection of gastric cancer. Cancer Res 74 (Suppl 19): S892-S892, 2014

34. Tsai CY, Wang CS, Tsai MM, Chi HC, Cheng WL, Tseng YH, Chen CY, Lin CD, Wu JI, Wang LH, et al: Interleukin-32 increases human gastric cancer cell invasion associated with tumor progression and metastasis. Clin Cancer Res 20: 2276-2288, 2014

35. Koh SA, Kim MK, Lee KH, Kim SW and Kim J-R: RhoGDI2 is associated with HGF-mediated tumor invasion through VEGF in stomach cancer. Clin Exp Metastasis 31: 805-815, 2014.

36. Bienz $M$ and Clevers H: Linking colorectal cancer to Wnt signaling. Cell 103: 311-320, 2000

37. Doucas H, Garcea G, Neal CP, Manson MM and Berry DP: Changes in the Wnt signalling pathway in gastrointestinal cancers and their prognostic significance. Eur J Cancer 41: 365-379, 2005.

38. Song DH, Kaufman JC, Borodyansky L, Albanese C, Pestell RG and Wolfe MM: Gastrin stabilises $\beta$-catenin protein in mouse colorectal cancer cells. Br J Cancer 92: 1581-1587, 2005. 